\title{
Unmanned aerial vehicle measurements of volcanic carbon
}

\section{dioxide fluxes}

\author{
A. J. S. McGonigle, ${ }^{1}$ A. Aiuppa, ${ }^{2}$ G. Giudice, ${ }^{3}$ G. Tamburello, ${ }^{2}$ A. J. Hodson, ${ }^{1}$ \\ and S. Gurrieri ${ }^{3}$ \\ Received 29 October 2007; revised 1 February 2008; accepted 12 February 2008; published 20 March 2008.
}

[1] We report the first measurements of volcanic gases with an unmanned aerial vehicle (UAV). The data were collected at La Fossa crater, Vulcano, Italy, during April 2007, with a helicopter UAV of $3 \mathrm{~kg}$ payload, carrying an ultraviolet spectrometer for remotely sensing the $\mathrm{SO}_{2}$ flux $\left(8.5 \mathrm{Mg} \mathrm{d}^{-1}\right)$, and an infrared spectrometer, and electrochemical sensor assembly for measuring the plume $\mathrm{CO}_{2} / \mathrm{SO}_{2}$ ratio; by multiplying these data we compute a $\mathrm{CO}_{2}$ flux of $170 \mathrm{Mg} \mathrm{d}^{-1}$. Given the deeper exsolution of carbon dioxide from magma, and its lower solubility in hydro-thermal systems, relative to $\mathrm{SO}_{2}$, the ability to remotely measure $\mathrm{CO}_{2}$ fluxes is significant, with promise to provide more profound geochemical insights, and earlier eruption forecasts, than possible with $\mathrm{SO}_{2}$ fluxes alone: the most ubiquitous current source of remotely sensed volcanic gas data. Citation: McGonigle, A. J. S., A. Aiuppa, G. Giudice, G. Tamburello, A. J. Hodson, and S. Gurrieri (2008), Unmanned aerial vehicle measurements of volcanic carbon dioxide fluxes, Geophys. Res. Lett., 35, L06303, doi:10.1029/2007GL032508.

\section{Introduction}

[2] Recent advances in unmanned aerial vehicle (UAV) technology are set to revolutionise the geosciences in the coming decades. These platforms are unique in their ability to rapidly provide high spatial resolution data over large areas, at a fraction of the cost of conventional manned aircraft surveys. With units now available with autonomous flight capability, payloads of 10s of kgs and endurances of $1000 \mathrm{~s}$ of kms, UAVs are now beginning to find utility in a wide range of atmospheric science, and land and ocean remote sensing applications [e.g., Lin, 2006; Watai et al., 2006; Ramanathan et al., 2007]. They are also particularly suitable for measurements in hostile environments, such as on volcanoes, where UAVs have recently been used to record visible and infrared imagery [Buschmann et al., 2006; Patterson et al., 2006], and to perform aeromagnetic surveys [Funaki, 2005]. In this paper, we report what, to the best of our knowledge, are the first measurements of volcanic gases with a UAV, based the recent technological developments of a suitable flight platform, and sufficiently light sensors for this to porter.

[3] Volcanic gas data are important diagnostics of underground magmatic conditions, with utility in eruption forecasting. Remote sensing is increasingly the methodology of

\footnotetext{
${ }^{1}$ Department of Geography, University of Sheffield, Sheffield, UK.

${ }^{2}$ Dipartimento CFTA, Università di Palermo, Palermo, Italy.

${ }^{3}$ Istituto Nazionale di Geofisica e Vulcanologia, Palermo, Italy.
}

Copyright 2008 by the American Geophysical Union. 0094-8276/08/2007GL032508\$05.00 choice for these observations, given its intrinsic safety; paramount among these observations are spectroscopic measurements of $\mathrm{SO}_{2}$ fluxes, given the ease with which this plume species can be measured in the atmosphere, against the low background ambient concentrations [McGonigle, 2005]. Whilst useful scientific insight have been obtained with such data [e.g., Sutton et al., 2001], $\mathrm{SO}_{2}$ is not an ideal gas for single species volcano-geochemical investigation; rather, $\mathrm{CO}_{2}$, which begins to exsolve from the melt at higher confining pressures, and is less soluble in intervening hydrothermal systems, is a far more promising target species, capable of providing deeper geochemical insights and early eruption forewarnings [e.g., Hernández et al., 2001].

[4] Over the last decades there has been great interest in developing a remote sensing approach for measuring volcanic $\mathrm{CO}_{2}$ fluxes. However, such efforts have proven futile hitherto, owing to the difficulty of spectroscopically resolving the volcanic plumes' $\mathrm{CO}_{2}$ above the high atmospheric column amounts, and the poor field portability, and the high cost and power budgets of $\mathrm{CO}_{2}$ LIDAR systems. Whilst a number of workers have made $\mathrm{CO}_{2}$ flux measurements with manned aircraft and in-plume sensors [McGee, 1992; Koepenick et al., 1996], this methodology is expensive to implement on a routine basis, and exposes the monitoring personnel to risk, for flights in the vicinity of active volcanoes.

[5] Here we report a novel UAV approach for volcanic $\mathrm{CO}_{2}$ flux determination, which provides the potential for completely remote measurements, thereby vastly reducing observational risk. The methodology involves firstly traversing beneath the plume to spectroscopically determine the volcano's $\mathrm{SO}_{2}$ flux, then flying into the plume to sample its $\mathrm{CO}_{2} / \mathrm{SO}_{2}$ ratio (see Figure 1); combining these data results in the $\mathrm{CO}_{2}$ flux. This is only now possible based on the recent development of miniaturised instrumentation for these two measurements: a compact USB powered UV spectrometer [McGonigle et al., 2002; Galle et al., 2003], and the combination of an electrochemical $\mathrm{SO}_{2}$ sensor, and infrared $\mathrm{CO}_{2}$ analyser (collectively, a so called Multi-GAS unit) [Aiuppa et al., 2005; Shinohara, 2005], respectively. This empirical advance in unmanned aerial vehicle applications builds upon the recent development of a ground based robotic vehicle for volcanic surveillance [Muscato et al., 2003].

\section{Methodology}

[6] The measurement methodology is shown in Figure 1. The UAV was a Thunder Tiger Raptor 90 helicopter, with a $15 \mathrm{cc}$ internal combustion engine, flown with Morgan Fuel 
(B) Climb to make in-plume

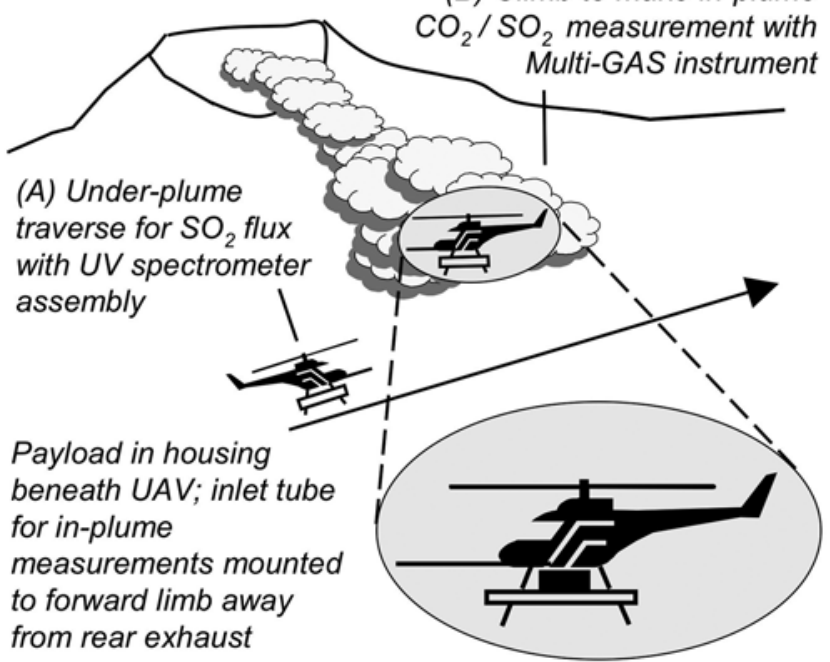

Figure 1. Experimental configuration for performing the UAV remotely sensed $\mathrm{SO}_{2}$ flux measurements, and in-plume $\mathrm{CO}_{2} / \mathrm{SO}_{2}$ ratio measurements.

Cool Power 30-LS (e.g., methanol based with 30\% nitromethane) fuel, and $710 \mathrm{~mm}$ standard carbon fibre blades. Without payload, the aircraft weighed $5.2 \mathrm{~kg}$, and with the instrumentation, it had a top speed of $\approx 45$ knots with up to $16 \mathrm{~km}$ endurance (12 minutes flight time) from each fuel tank. The helicopter dimensions were $1410 \times 465 \times$ $190 \mathrm{~mm}$, and it could be readily disassembled and packed in a suitcase for check-in baggage air transportation. The UAV was mounted on top of a $400 \mathrm{~mm}$ high four legged base, to avoid ash intake to the engine during take-off and landing, and to which the payload was attached using a $\approx 250 \times 400 \mathrm{~mm}$ equipment tray, which was vibrationally damped to avoid any disruption of the payload computer's spinning hard drive. The helicopter was flown manually via a radio link, and good visual control of the UAV was possible up to distances of $\approx 400 \mathrm{~m}$ from the pilot; this range could be extended considerably using binoculars, however. The performance of the aircraft was not significantly reduced when loaded with the up to $3 \mathrm{~kg}$ instrumentation, implying that yet heavier payloads may be feasibly transported with this UAV.

[7] Two payload modules were used; the first of which was a $1.5 \mathrm{~kg}$ ultraviolet spectrometer assembly for measuring $\mathrm{SO}_{2}$ fluxes. This consisted of a Fujitsu-Siemens P1510 ultra-compact notebook computer, an Ocean Optics USB2000 spectrometer $(245-400 \mathrm{~nm}$ and $\approx 0.5 \mathrm{~nm}$ spectral range and resolution, respectively), coupled via an optical fibre (Avantes, FCRL-4UV200-2-SR) to an in-house built, vertically pointing telescope $\left(5 \mathrm{~cm}\right.$ length, $\approx 5^{\circ}$ field of view), and a Garmin E-Trex GPS receiver. This module was traversed below the plume, capturing georeferenced spectra every $\approx 2 \mathrm{~s}$, from which overhead $\mathrm{SO}_{2}$ concentrations were determined, and integrated across a plane perpendicular to the plume transport vector. This integrated column amount was then multiplied by the plume transport speed (determined manually, from the crater rim, using an anemometer at plume altitude) to output the $\mathrm{SO}_{2}$ flux. More detail on the traverse based volcanic $\mathrm{SO}_{2}$ flux measurement is provided by McGonigle [2007].

[8] The second, Multi-GAS, payload module weighed $3 \mathrm{~kg}$, and consisted of an Edinburgh Instruments Gascard II IR spectrometer, for $\mathrm{CO}_{2}$ concentration measurements (detection limit: 1 ppm; error: $2 \%$ ), and an electrochemical sensor (Membrapor, SO2-S-100; detection limit: $0.5 \mathrm{ppm}$; error: $2 \%$ ) for $\mathrm{SO}_{2}$ concentrations [Aiuppa et al., 2005]. The system was powered using a $12 \mathrm{~V}, 7 \mathrm{Ah}$ lead acid battery, and the results, georeferenced using a Garmin E-Trex GPS receiver, were captured to a home-made data logger board every $\approx 2 \mathrm{~s}$. The gases were pumped into the Multi-GAS unit using a miniature $11 \mathrm{~min}^{-1}$ pump (KNF, NMP 015M), via a PTFE tube, which had an aerosol filter on its inlet and protruded $1 \mathrm{~m}$ from the front of the helicopter on a supporting limb. The time delay between gas entering the sampling tube and the sensors responding was $\approx 5 \mathrm{~s}$. The payloads' performances did not appear to be influenced in any way during flight, versus when operating from the ground; in particular, there was no contamination caused by the exhaust, by virtue of the efficient purging action of the helicopter blades' downdraft. At the time of writing, the overall cost for both payload modules, and the helicopter itself was $\approx \$ 12 \mathrm{k}$. Whilst no flight permissions were required during this project, other workers seeking to deploy on UAVs on volcanoes are recommended to consult, in advance, the appropriate aviational authority.

\section{Results and Discussion}

[9] Eight traverses were performed underneath the plume of La Fossa crater, Vulcano on April 1, 2007, with the first payload module, in order to determine the volcano's $\mathrm{SO}_{2}$ flux. This volcano has a $0.045 \mathrm{~km}^{3}$ active fumarolic field within its northern crater sector, ranging from its lower slopes to the rim, and the wind blew to the north throughout our campaign. The transects were made $\leq 200 \mathrm{~m}$ downwind of the crater rim, and take-off, landing and piloting were achieved from points on the crater rim, outside the plume boundaries, for all the measurements reported in this paper. The fluxes obtained from each measurement were: 0.11 , $0.079,0.10,0.096,0.10,0.11,0.094$ and $0.095 \mathrm{~kg} \mathrm{~s}^{-1}$, respectively (averaging $0.098 \mathrm{~kg} \mathrm{~s}^{-1} ; 8.5 \mathrm{Mg} \mathrm{d}^{-1}$ ). We estimate the error in this datum at $25 \%$, arising from uncertainty in the spectral $\mathrm{SO}_{2}$ concentration retrievals $( \pm 15 \%)$, and in the plume transport speed measurement $( \pm 20 \%)$. Sample plots of the plume structure, inferred from four of these traverses are shown in Figure 2.

[10] Twenty two minutes of in-plume measurements with the second payload, were achieved on April 5, 2007, by hovering the helicopter $\approx 10-100 \mathrm{~m}$ downwind of the crater rim. The results of these surveys are shown in Figure 3, detailing $\mathrm{CO}_{2}$ vs. $\mathrm{SO}_{2}$ concentrations for each measurement. By computing the line of best fit to this plot, and accounting for uncertainty in this process, we estimate the bulk plume $\mathrm{CO}_{2} / \mathrm{SO}_{2}$ ratio at $30 \pm 5$, and therefore the $\mathrm{CO}_{2}$ flux to be $2.0 \pm 0.6 \mathrm{~kg} \mathrm{~s}^{-1}\left(170 \pm 51 \mathrm{Mg} \mathrm{d}^{-1}\right)$. This bulk plume ratio is in good agreement with that (35) reported recently for Vulcano's plume by Aiuppa et al. [2005], and falls within the range (20-45) measured from the ground with MultiGAS, for the individual fumaroles, during our campaign (April 5). The modest fluxes detailed in this paper, in 

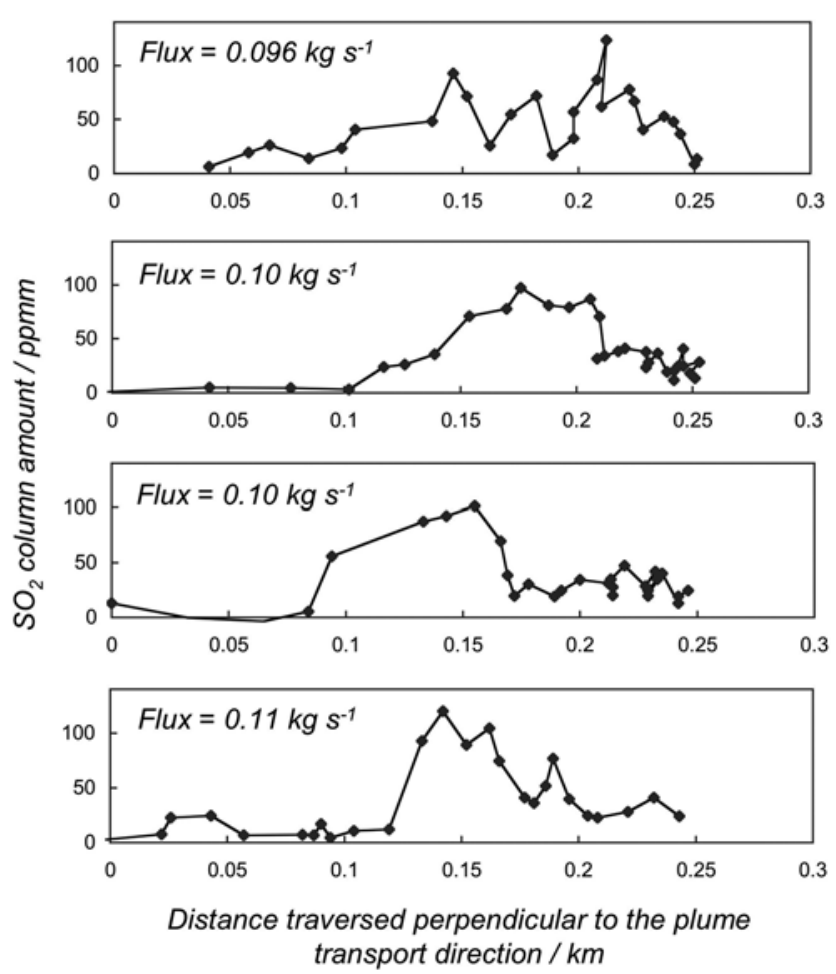

Figure 2. $\mathrm{SO}_{2}$ column amount profiles of Vulcano's plume as determined by the under plume traverses with the ultraviolet spectrometer payload. $\mathrm{SO}_{2}$ fluxes are shown for each measurement.

common with those reported by Aiuppa et al. [2005] (18 and $420 \mathrm{Mg} \mathrm{d}^{-1}$ for $\mathrm{SO}_{2}$ and $\mathrm{CO}_{2}$, respectively), indicate the presently low level of activity of this volcano.

[11] This proof of concept study shows the excellent potential of helicopter UAVs in volcanic gas monitoring, for both in-plume and spectroscopic remote sensing configurations. By virtue of their capacity to hover, and for stable flight at low speeds (thereby providing as many in-plume data points as possible), in the rapid and turbulent wind fields near volcanic summits, such devices are, in principle, better suited to this application than fixed wing aircraft. In addition, helicopter UAVs also show promise for other, e.g., thermal camera, volcanic measurements, for remote deployment of instrumentation on volcanoes, and for studies of the chemical evolution of volcanic plumes as they advect from source [e.g., Bobrowski et al., 2007], thereby improving our understanding of the impacts of these volatiles upon the atmosphere and climate. For a further discussion on the merits of helicopter versus fixed wing UAVs in the context of this, and other, applications see [Saggiani and Teodorani, 2004].

[12] Our UAV was an inexpensive $(\approx \$ 2000)$ off the shelf radio controlled model, which fared remarkably well in this context, given its non purpose-build design; e.g., the flight performance was not diminished following exposure to the acidic plume gases. This work opens the way for the implementation of scaled helicopters of larger fuel tanks (to allow $\geq 50$ minutes flight time) and carrying capacity (e.g., able to simultaneously porter both payload modules described here), petrol or turbine engines (providing enhanced performance at altitude), autonomous flight capa- bility, ash filters for the air inlets to mitigate against engine corrosion, and real time telemetry of the sensor data to provide confidence that the helicopter is correctly located with respect to the plume, throughout measurements. Such units could be flown with a minimum of training, with take off and landing achieved from completely safe locations, multiple kms from the source. By programming these UAVs to fly into the wind at plume altitude, and recording ground and air speed in each case, the plume transport rate could be accurately computed via subtraction, thereby addressing the primary error source in volcanic flux measurements, in addition [e.g., McGonigle et al., 2005; Williams-Jones et al., 2006].

\section{Concluding Remarks}

[13] We have demonstrated volcanic gas measurements with an unmanned aerial vehicle: a helicopter of $3 \mathrm{~kg}$ payload, which we deployed on La Fossa crater, Vulcano, Italy during April 2007 to measure the volcano's $\mathrm{SO}_{2}$ flux by traversing underneath the plume with a vertically pointing ultraviolet spectrometer. We also measured the in-plume $\mathrm{CO}_{2} / \mathrm{SO}_{2}$ ratio, using an electrochemical sensor and an infrared spectrometer; combining these data yielded a $\mathrm{CO}_{2}$ flux of $170 \mathrm{Mg} \mathrm{d}^{-1}$. This study confirms the excellent potential of helicopter UAVs in volcanology, given their good stability in the turbulent wind fields surrounding volcanoes, and their ability to hover, or fly at slow speeds, providing scope for longer data acquisitions, per plume transect, than possible with fixed wing aircraft. The capability to remotely monitor volcanic $\mathrm{CO}_{2}$ fluxes is significant, given the deep exsolution of this species, and its low solubility in hydrothermal systems; in these respects carbon dioxide data show far greater potential for eruption forecasting, that the $\mathrm{SO}_{2}$ fluxes currently monitored to this end. This methodology also removes the risk to scientists associated with the alternative strategy of deploying Multi-GAS units on crater edges in order to determine $\mathrm{CO}_{2}$ fluxes, where the devices are, in addition, liable to destruction in the event of explosions. The competence to measure $\mathrm{CO}_{2} /$ $\mathrm{SO}_{2}$ using the helicopter is furthermore of importance in its own right, independent of its role in the flux computation,

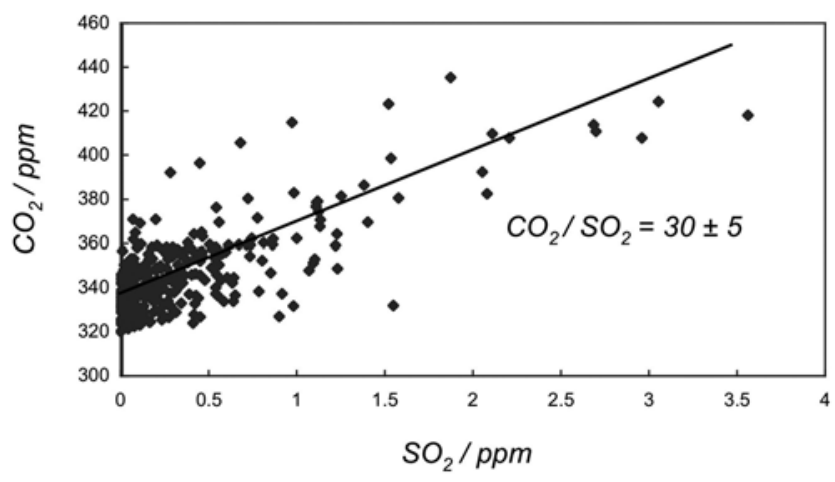

Figure 3. Carbon dioxide versus sulphur dioxide concentrations, measured in Vulcano's plume, using the electrochemical sensor and infrared spectrometer (Multi-GAS) assembly. The mean $\mathrm{CO}_{2} / \mathrm{SO}_{2}$ ratio of $30 \pm 5$ was determined from the gradient of the line of best fit to these data. 
given the significance of this ratio as a geochemical proxy for underground magmatic conditions.

[14] Acknowledgments. A.M. acknowledges support of a RCUK Academic Fellowship. We thank David Fisher for his invaluable and highly professional support with piloting and building the helicopter, and Gomez Aiuppa for his logistical support. We also thank David Pyle and an anonymous reviewer for their very helpful remarks.

\section{References}

Aiuppa, A., C. Federico, G. Giudice, and S. Gurrieri (2005), Chemical mapping of a fumarolic field: La Fossa Crater, Vulcano Island (Aeolian Islands, Italy), Geophys. Res. Lett., 32, L13309, doi:10.1029/ 2005GL023207.

Bobrowski, N., R. von Glasow, A. Aiuppa, S. Inguaggiato, I. Louban, O. W. Ibrahim, and U. Platt (2007), Reactive halogen chemistry in volcanic plumes, J. Geophys. Res., 112, D06311, doi:10.1029/2006JD007206.

Buschmann, M., L. Krüger, P. Vörsmann, F. Böker, and P. Ramon (2006), Volcano observation with the Autonomous Mini-Aeroplane "Carolo," paper presented at Cities on Volcanoes 4 Meeting, Cities and Volcanoes Comm., Quito, Ecuador, 23-27 Jan.

Funaki, M. (2005), A trial of the aeromagnetic survey by a small unmanned aerial vehicle at Mt. Choktai volcano, Japan, paper presented at 10th IAGA Scientific Assembly, Int. Assoc. of Geomagn. and Aeron. Toulouse, France, 18-29 Jul.

Galle, B., C. Oppenheimer, A. Geyer, A. J. S. McGonigle, M. Edmonds, and L. A. Horrocks (2003), A miniaturised UV spectrometer for remote sensing of $\mathrm{SO}_{2}$ fluxes: A new tool for volcano surveillance, J. Volcanol. Geotherm. Res., 119, 241-254, doi:10.1016/S0377-0273(02)00356-6.

Hernández, P. A., K. Notsu, J. M. Salazar, T. Mori, G. Natale, H. Okada, G. Virgili, Y. Shimoike, M. Sato, and N. M. Pérez (2001), Carbon dioxide degassing by advective flow from Usu volcano, Japan, Science, 292, 83-86, doi:10.1126/science. 1058450 .

Koepenick, K. W., S. L. Brantley, J. M. Thompson, G. L. Rowe, A. A. Nyblade, and C. Moshy (1996), Volatile emissions from the crater and flank of Oldoinyo Lengai volcano, Tanzania, J. Geophys. Res., 101, $13,819-13,830$.

Lin, P. H. (2006), Observations: The first successful typhoon eyewallpenetration reconnaissance flight mission conducted by the unmanned aerial vehicle, Aerosonde, Bull. Am. Meteorol. Soc., 87, 1481-1483, doi:10.1175/BAMS-87-11-1481.

McGee, K. A. (1992), The structure, dynamics and chemical-composition of noneruptive plumes from Mt. St. Helens, 1980-1988, J. Volcanol. Geotherm. Res., 51, 269-282, doi:10.1016/j.jvolgeores.2007.02.001.

McGonigle, A. J. S. (2005), Volcano remote sensing with ground based spectroscopy, Philos. Trans. R. Soc. Ser. A, 363, 2915-2929, doi:10.1098/ rsta.2005.1668.
McGonigle, A. J. S. (2007), Measurement of volcanic $\mathrm{SO}_{2}$ fluxes with differential optical absorption spectroscopy, J. Volcanol. Geotherm. Res., 162, 111-122, doi:10.1016/j.jvolgeores.2007.02.001.

McGonigle, A. J. S., C. Oppenheimer, B. Galle, T. A. Mather, and D. M. Pyle (2002), Walking traverse and scanning DOAS measurements of volcanic gas emission rates, Geophys. Res. Lett., 29(20), 1985, doi:10.1029/2002GL015827.

McGonigle, A. J. S., D. R. Hilton, T. P. Fischer, and C. Oppenheimer (2005), Plume velocity determination for volcanic $\mathrm{SO}_{2}$ flux measurements, Geophys. Res. Lett., 32, L11302, doi:10.1029/2005GL022470.

Muscato, G., et al. (2003), ROBOVOLC: A robot for volcano exploration result of first test campaign, Ind. Robot, 30, 231-242, doi:10.1108/ 01439910310473942.

Patterson, M. C. L., A. Mulligan, J. Douglas, J. Robinson, and L. J. Wardell (2006), Development of unmanned autonomous vehicles (UAVs) for volcano surveillance, paper presented at Cities on Volcanoes 4 Meeting, Cities and Volcanoes Comm., Quito, Ecuador, 23-27 Jan.

Ramanathan, V., M. V. Ramana, G. Roberts, D. Kim, C. Corrigan, C. Chung, and D. Winkler (2007), Warming trends in Asia amplified by brown cloud solar absorption, Nature, 448, 575-578, doi:10.1038/ nature 06019 .

Saggiani, G. M., and B. Teodorani (2004), Rotary wing UAV potential applications: An analytical study through a matrix method, Aircraft Eng. Aerosp. Technol., 76, 6-14, doi:10.1108/00022660410514955.

Shinohara, H. (2005), A new technique to estimate volcanic gas composition: Plume measurements with a portable multi-sensor system, J. Volcanol. Geotherm. Res., 143, 319-333, doi:10.1016/j.jvolgeores.2004.12.004.

Sutton, A. J., T. Elias, T. M. Gerlach, and J. B. Stokes (2001), Implications for eruptive processes as indicated by sulfur dioxide emissions from Kilauea Volcano, Hawaii, 1979-1997, J. Volcanol. Geotherm. Res., 108, 283-302, doi:10.1016/S0377-0273(00)00291-2.

Watai, T., T. Machida, N. Ishizaki, and G. Inoue (2006), A lightweight observation system for atmospheric carbon dioxide concentration using a small unmanned aerial vehicle, J. Atmos. Oceanic Technol., 23, 700710, doi:10.1175/JTECH1866.1.

Williams-Jones, G., K. Horton, T. Elias, H. Garbeil, P. J. Mouginis-Mark, A. J. Sutton, and A. J. L. Harris (2006), Accurately measuring volcanic plume velocity with multiple UV spectrometers, Bull. Volcanol., 68, 328-332, doi:10.1007/s00445-005-0013-x.

A. Aiuppa and G. Tamburello, Dipartimento CFTA, Università di Palermo, Via Arcmirafi 36, Palermo, I-90123, Italy.

G. Giudice and S. Gurrieri, Istituto Nazionale di Geofisica e Vulcanologia, Via Ugo La Malfa 153, Palermo, I-90146, Italy.

A. J. Hodson and A. J. S. McGonigle, Department of Geography, University of Sheffield, Sheffield, S10 2TN, UK. 